\section{Uma arte exuberante e compromissada: Gori Muñoz em} três tempos

A comitteed and exuberant art: Gori Muñoz in three different times

Margareth dos Santos
Doutora em Literatura Espanhola pela USP, professora do Departamento de Letras Modernas da Universidade de São Paulo (USP). Suas linhas de pesquisa compreendem o exame das relações entre literatura, história e arte no século $X X$, tanto na Espanha como no contexto ibero-americano na produção vinculada à Guerra Civil Espanhola e ao pós-guerra civil espanhola. E-mail: marsanto@usp.br Brasil 
Gregorio Muñoz Montoro, conhecido como Gori Muñoz (Valencia,1906 Buenos Aires,1978) foi um artista plástico que desde muito jovem destacou-se por suas múltiplas facetas: ilustrador, desenhista e caricaturista. Ao longo de sua trajetória, colaborou com diversos jornais e revistas, mas foi com o impulso das vanguardas dos anos 1920 e com o compromisso político e ideológico com a II República espanhola que seu talento ganhou projeção internacional. Ao trabalhar com o pintor e cartelista Josep Renau na Dirección General de Bellas Artes de Valencia (setembro de 1936 a abril de 1938) e, posteriormente, no Pabellón de España da Exposição Internacional de Paris de 1937, no qual Gori Muñoz cumpriu um papel decisivo na conformação de um discurso artístico desconcertante sobre o golpe de estado impetrado ao governo legítimo da II República e ignorado pelas potências europeias.

Responsável pela cenografia do Pabellón, Gori criou um percurso impactante para os espectadores, cujo movimento partia do exterior ao interior do edifício e, utilizando-se de fotomontagens, representava uma demonstração artística e social vigorosa de vanguarda. Em sua totalidade, o projeto propunha um convívio fluído entre fotografia, arte figurada, cinema, artesanato e dança folclórica. Apesar do conturbado contexto político, graças à proposta de Gori e de Renau, a Espanha pôde exibir para o mundo uma situação articulada por distintos discursos artísticos constitutivos de seu povo.

Embora o pavilhão espanhol de 1937 tenha configurado uma forma eficaz de denúncia sócio-política, a Guerra Civil Espanhola seguiu seu rumo e Gori Muñoz retornou à Espanha, onde militou como um destacado ativista da Seção de Artes Plásticas da Alianza de Intelectuais Antifascistas. Concluída 
a guerra, como milhares de espanhóis, foi parar em um dos vários campos de concentração armados pelos franceses, posteriormente, graças à ação de amigos e de sua esposa, María del Carmen García Antón, estudante de medicina e atriz de La Barraca, conseguiu liberar-se para, em seguida, partir com sua família rumo ao exílio na Argentina, do qual, nunca voltaria.

Durante seu exílio, Gori continuou seu trabalho como ilustrador em várias revistas (Pensamiento Español) e editoras (Atlántida, Losada, Renacimiento, Aguilar, Schapire, Bajel). Montou exposiçóes de pintura (El teatro en silencio, Carpeta de viajes, Paris vista por Gori, Toros) e publicou artigos sobre cinema, assim como textos e livros (Méliès, Toros e Toreros del Río de la Plata, Ni en cap mapa ni en cap història, Daumier, Pequeño itinerario bélico del hambre, Cuando Buenos Aires era Colonia).

$\mathrm{Na}$ capital argentina, pôde retomar seu trabalho como cenógrafo e diretor de arte, com um expressivo número de atuações: 192 filmes (1941-1973) - muitos deles premiados - e 162 montagens teatrais em Buenos Aires e Montevidéu, de autores clássicos e modernos. Em todos esses espaços propôs inovaçóes por onde passava.

Essa trajetória prodigiosa se expóe por meio da entrevista realizada com María Antonia Muñoz-Malajovich ${ }^{1}$, filha caçula de Gori, e grande entusiasta da trajetória do pai. Por meio desse diálogo (que contou com a

1 Bióloga (FCEN-UBA, Argentina; UFRJ, Brasil), atua na área de divulgação e ensino de Biotecnologia, sendo autora de artigos e livros publicados no Brasil e na Argentina. Filha caçula de Gori Muñoz, editora da página-web dedicada à sua memória (Gori Muńoz, http://gorimunoz. com), com fotos inéditas e lembranças pessoais do acervo dela e de sua irmã Carmen MuñozBernand. 
participação de Carmen Muñoz-Bernand, filha de Gori Muñoz nascida na França em setembro de 1939 e criada na Argentina com a irmã), a revista Caracol pôde recuperar momentos de inflexão da vida do artista, que traduzem um itinerário imprescindível para pensar a voz dos derrotados, reviver histórias ligadas às consequências da Guerra Civil Espanhola, reaver palavras silenciadas pela ditadura franquista, recobrar marcos históricos que dizem respeito à Espanha, à América-latina e a todos que se preocupam pela defesa da arte como expressão do sujeito frente ao mundo, o que significa muito nos tempos em que vivemos. Portanto, ler o percurso desse valenciano falecido em 1978, sem nunca ter voltado à Espanha, nos concerne a todos.

\section{Margareth Santos: Como era seu pai?}

María Antonia Muñoz-Malajovich: Solar, com uma exuberância mediterrânea. De inteligência rápida e vasta cultura. Firme e coerente com seus princípios sociais e republicanos. Curioso e com agudo senso de humor. Gostava de uma boa mesa. Fiel amigo de seus amigos e grande conversador. Cordial e, no entanto, capaz de explodir em ataques de raiva que passavam como tempestade de veráo. Malparlat.

Trabalhador contumaz, dormia muito pouco. Além de suas atividades em estúdios cinematográficos e teatros, levava uma vida social intensa. Contudo, sempre encontrava algum tempo para pintar. Tinha como divisa Faire le métier qu'on aime et aimer la vie dans les plus petites choses. 


\section{M.S.: Que papel desempenhou seu pai na II República? Gori Muñoz comentou em que frentes atuou durante esse período?}

M.A.M.M: Na proclamação da II República, em 1931, ele tinha 25 anos de idade. Filho do pintor e ceramista Gregorio Muñoz Dueñas, teve contato com as artes desde sua primeira infância em Benicalap ${ }^{2}$, na huerta de Valência. Em 1916, a família se mudou para Manises e, mais tarde, para Valência, depois, Madri. Em 1923, recebeu sua primeira bolsa da Junta de Ampliación de Estudios e Investigaciones Cientificas (categoria desenho) que o levou para a França. Após a morte do pai, abandonou os estudos de Bellas Artes e Arquitectura e começou a expor seus trabalhos como caricaturista em Madri e no Ateneo Comercial de Valencia.

Estava, portanto, à época, iniciando sua carreira profissional, se destacando como ilustrador $^{3}$, desenhista ${ }^{4}$ e caricaturista em vários jornais. Em 1933, ele obteve sua segunda bolsa da Junta de Ampliación de Estudios e Investigaciones Cientificas e voltou novamente a Paris, onde seguiu o curso de composição decorativa de Fernand Léger.

De regresso a Madrid, recebeu várias encomendas importantes: murais para a Embaixada de Santo Domingo, ilustração do catálogo e montagem da

2 Ele descreve essa infância feliz em seu livro Ni en cap mapa, ni en cap història (Rosa Peralta Ed., Universitat de Valencia, 2007), escrito em língua valenciana e espanhola, a obra inclui textos sobre Daumier e o relato Pequeño itinerario del hambre.

3 Elaborou a capa do livro de Gregorio Marañon Amor, Conveniência y Eugenesia (Madrid, 1931) e ilustrações para os editoriais Bolaño e Aguilar.

4 Recebeu o Premio del Salón de carteles publicitarios outorgado pela Unión de Dibujantes Españoles pelo cartaz Aceites San Rafael. 
exposição Iglesias de Etnografía Amazónica. Também decorou com pinturas murais a embarcação Ártabro, na qual ele figuraria como desenhista em uma exposição que, segundo suas próprias palavras "entraría por el Amazonas y saldría por el Orinoco". Um grande sonho que nunca chegou a realizar.

A Guerra Civil Espanhola (julho de 1936) o encontrou em Paris, com outra bolsa da Junta de Ampliación de Estudios e Investigaciones Cientificas. Voltou imediatamente à Espanha, via Irún, onde se integrou ao combate e entrou para o Servicio de Información del Estado Mayor Central. Eu o ouvi falar repetidas vezes sobre as dificuldades em conseguir armamento para o exército republicano. Em um país cortado em dois pelos sublevados, as armas tinham que ser transferidas da Catalunha ao País Basco. Ele relatava como, com a ajuda dos cheminots, ele e dois companheiros atravessaram várias vezes a França transportando armas, até serem presos em Toulouse.

Novamente em Valência, ele se incorporou à Aliança d' Intel-lectuals per a Defensa da Cultura e colaborou em várias revistas. Também realizou os desenhos das fallas Els enemics del poble al enfer que não chegaram a acontecer porque o dinheiro foi utilizado para comprar comida, além, claro, de pairar sob todos as ameaças do General Queipo de Llano, que em suas emissóes radiofônicas afirmava que bombardearia Valência, caso se dispusessem as fallas nas ruas da cidade.

Colaborador de Josep Renau, a fins de maio de 1937, ele viajou a Paris com Félix Alonso e Alberto Sánchez, para preparar o pavilhão da Espanha na Exposição Internacional de Paris. Assinou com Félix Alonso o Taller de Decoración (parte fixa e parte móvel) e participou da elaboraçáo 


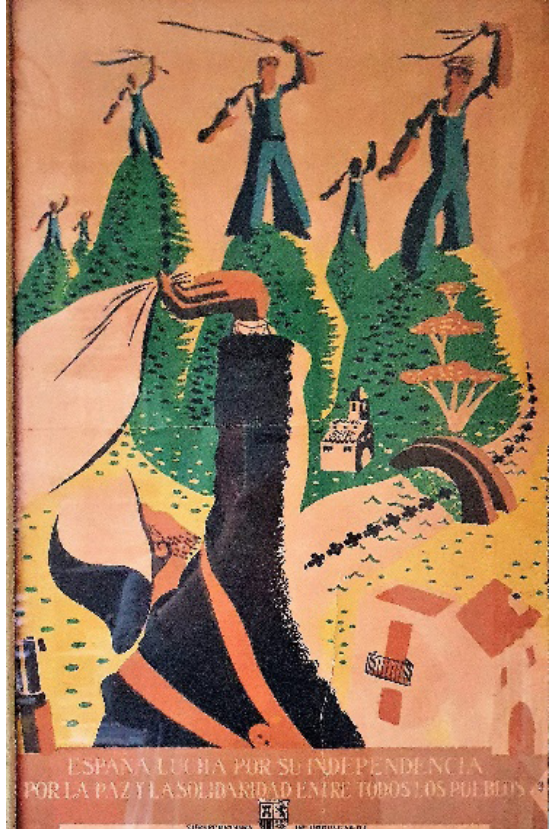

Cartaz elaborado por Gori Muñoz para a Subsecretaría de propaganda da II República, 1938. Acervo de María Antonia MuñozMalajovich. das fotomontagens e da composição dos textos.

M.S.: O que seu pai comentava sobre Pavilháo Espanhol de 1937? Ele descreveu, em algum momento, como era o convívio com outros intelectuais e artistas durante a montagem do Pavilháo?

M.A.M.M: Sempre destacou a modernidade do pavilhão, sua estrutura e a dificuldade de mantê-lo vivo com uma realidade que mudava dia-adia. Comentava sobre as tertúlias no Cosmos, e descrevia com empolgação a instalação do "Guernica", a fonte de

Almadén, a escultura de Alberto e da inveja que Dalí tinha de Picasso. Ele também contava anedotas sobre minha mãe, María del Carmen García Antón, atriz do Teatro Universitário La Barraca, que trabalhava no Setor de Propaganda.

É dela a melhor narração sobre o ambiente do pavilhão, ao qual dedica um capítulo inteiro em suas memórias Visto al pasar. República, guerra y exilio 5 .

5 María del Carmen García Antón. Visto al Pasar: República, Guerra y Exilio. A Coruña: Ediçôes do Castro, 2002. 


\section{M:S.: Após a experiência com o Pavilhão, Gori Muñoz voltou à Espanha para assumir alguma função junto ao governo republicano? E como foi para ele o término da Guerra Civil Espanhola?}

M.A.M.M: Em dezembro de 1937, retornou a Barcelona. Abandonou as Juventudes Socialistas e se filiou ao Partido Comunista, sendo locado na Subsecretaria de Propaganda e atuando como assistente do General Rojo no Estado Mayor. A guerra avançou trazendo morte, fome e miséria. Ele relatou alguns episódios marcantes no texto Pequeño itinerario del hambre ${ }^{6}$. Em 1939, no início de fevereiro, Mari-Carmen e Gori, recém casados, fugiram de Barcelona rumo à França. Na terrível passagem de fronteira, foram separados pelas autoridades francesas. Grávida, ela conseguiu fugir de Boulou Perthus em um trem rumo a Paris. Internado em Argelès-sur-Mer, ele só foi liberado depois de vários meses. Reencontram-se em Paris, onde seus amigos Elio Obadía e Yves Lanancia os esconderam e os protegeram.

\section{M.S.: Como Gori Muñoz encarou a ideia do exílio? E como a família enfrentou essa situaçáo?}

M.A.M.M: $\mathrm{O}$ que pode fazer um homem sans papiers, com uma criança prestes a nascer, pressionado pelos franceses para se incorporar à Legiáo

6 Incluido em Ni en cap mapa ni en cap història. 


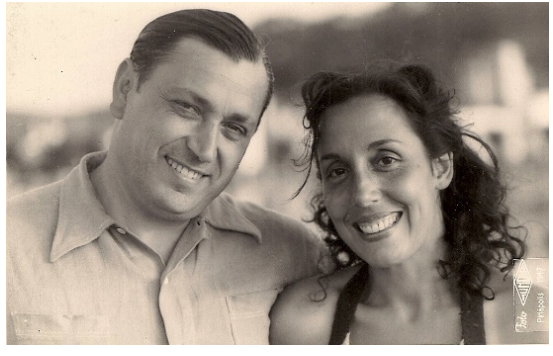

Gori Muñoz e Mari-Carmen. Piriápolis, 1947. Acervo de María Antonia MuñozMalajovich

Estrangeira no momento político em que é assinado o Pacto GermanoSoviético ? ? Partir.

Um mês após o nascimento de minha irmá - Carmen MuñozBernand -, eles embarcaram no navio Massilia rumo ao Chile, acolhidos pelo governo chileno mediante a intervenção de Pablo Neruda. Um fato nem sempre lembrado é que as passagens foram pagas pelos quakers.

Uma viagem difícil com um bebê recém-nascido e submarinos alemães rondando. Antes da chegada a Buenos Aires, o navio fez uma escala no Rio de Janeiro, onde a família foi entrevistada por jornais locais, curiosos em relação aos exilados espanhóis.

Ao aportarem na capital argentina, os refugiados foram impedidos de desembarcar. A intervenção de Natalio Botana, o diretor do poderoso jornal Crítica, junto ao presidente Ortiz, permitiu que os exilados espanhóis se radicassem no país. Amigos e numerosos simpatizantes da causa republicana os acolheram em Buenos Aires.

\section{M:S.: Uma vez na Argentina, como foi a inserção de Gori Muńoz nos meios culturais do país? Em que trabalhou?}

7 A cada vez que o Pacto Germano Soviético era mencionado, ele reagia com um "me c..., uno de los días más tristes de mi vida" 
M.A.M.M: Em Buenos Aires, atuou incialmente como desenhista para várias revistas, uma atividade que, embora o restringisse ao desenho de ornitorrincos, bolos e sobremesas, garantia o sustento familiar. Aliás, graças a Natalio Botana, meu pai foi contratado para trabalhar como desenhista na Editorial Atlántida. Ele também colaborou com ilustrações e capas em revistas culturais, como o Pensamiento Español e elaborou várias capas de livros de Rafael Alberti para a editora Bajel.

A oportunidade de trabalhar como cenógrafo se apresentou no teatro, com La Serrana de Ronda (1940), da companhia de Amalia Sánchez Ariño e Los cuernos de Don Friolera" (1940), da companhia de Helena Cortesina e Andrés Mejuto, nomes que contribuíram de maneira decisiva para sua atuação como cenógrafo na Argentina, outro destaque foi seu

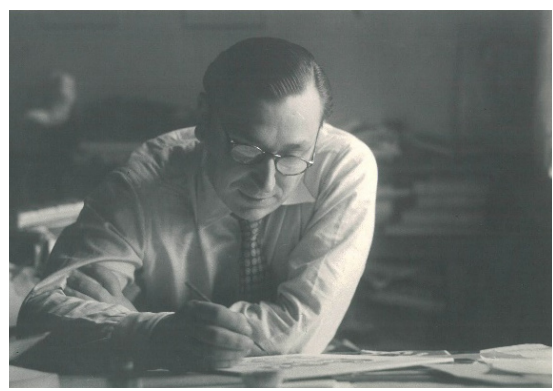

Gori Muñoz em sua mesa de trabalho. 1948-1950. Foto José Cañizares Fernández. Acervo de María Antonia Muñoz-Malajovich. trabalho em Mariana Pineda (1941), de Federico García Lorca, dirigida por María Teresa de León, com Rafael Alberti e Alejandro Casona no elenco.

Em relação ao cenário teatral, meu pai sempre afirmava que "el decorado debe servir a la obra y no la obra al decorado". Seguindo esse princípio, de 1940 até 1973, Gori realizou os cenários e figurinos de 162 montagens teatrais, em Buenos Aires e Montevidéu, para companhias espanholas e rioplatenses, incluindo comédias, dramas, espetáculos ao ar livre, musicais etc. 


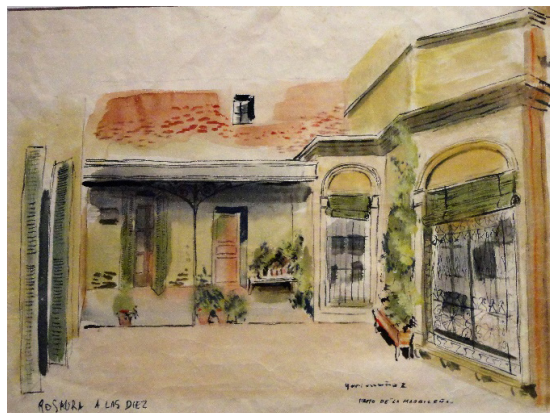

Croqui de Gori Muñoz para o filme Rosaura a las diez (1958) dirigida por Mario Soffici. Acervo de María Antonia MuñozMalajovich.

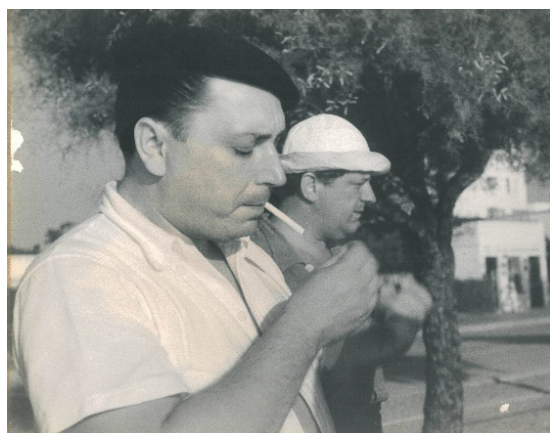

Gori Muñoz e Rafael Albert, em Punta del Este, 1950. Foto José Suarez. Acervo de María Antonia Muñoz-Malajovich.

Por exemplo, no teatro espanhol, Gori foi o cenógrafo de autores modernos, como Alejandro Casona e Federico García Lorca, e clássicos como Lope de Vega ou Cervantes. Atuou nas montagens de Margarita Xirgu ${ }^{8}$ em Buenos Aires e Montevidéu.

Eu me lembro com emoção das noites de estreia. A tensão antes da cortina levantar e o suspiro admirado da plateia ao visualizar o cenário e mergulhar no ambiente da representação.

Concomitante ao seu trabalho com o teatro, ele não deixou de pintar. Seu amor pelo teatro e pelo mistério do cenário vazio foi o tema das exposiçóes El Teatro en Silencio, (Galeria Pizarro, 1958; Centro Asturiano, 1969) que contaram com emotivas apresentaçóes de seus amigos Alejandro Casona e Rafael Alberti.

8 El alcalde de Zalamea (Comedia nacional del Uruguay, 1954), Peribañez y el Comendador de Ocaña (Teatro Solís, 1962) e Yerma (Teatro San Martín, com María Casares, 1963). 
M:S.: Além de trabalhar como ilustrador, cenógrafo e pintar, seu pai também colaborou em produçóes cinematográficas, não é mesmo? $\mathrm{O}$ que indica que a vida no exílio pressupunha açóes em várias frentes. Como se deram tais contribuiçóes?

M.A.M.M: No cinema, com Canción de Cuna (1941), o sucesso chegou rapidamente, abrindo um caminho promissor para sua capacidade artística. Para maiores detalhes, indico a obra de Rosa Peralta Gilabert, La Escenografía del exilio de Gori Muñoz', em que a crítica analisa sua trajetória com profundidade. Mas, de maneira resumida, posso dizer que entre 1941 e 1973, Gori Muñoz atuou como cenógrafo e diretor de arte em 192 filmes, dentre os quais, clássicos como La Dama Duende (1945), La pródiga (1945), Dios se lo pague (1947), Los Isleros (1951), Sangre negra (1951), Las aguas bajan turbias (1952), Rosaura a las diez (1958), El hombre de la esquina rosada (1962)...

Ao longo de seu trabalho, introduziu modificaçóes fundamentais na estrutura do cenário, tais como: eliminou o indefinido fundo de cena, encadeando os cenários de modo que um servia de fundo a outro, conseguindo assim uma unidade arquitetônica; reduziu a altura dos cenários de cinco a três metros e meio, possibilitando assim a introdução de melhorias na qualidade da iluminação; quebrou a rigidez linear dos cenários em forma de $\mathrm{U}$ e com ângulos retos que davam fundos iguais ou parecidos e adotou uma forma de trapézio que contribui para uma melhor qualidade do som; concedeu ao cenário uma constante de

9 Peralta Gilabert, Rosa. La Escenografia del Exilio de Gori Muñoz. Valencia: Ediciones de la Filmoteca. Instituto Valenciano de Cinematografía Ricardo Muñoz Suay, 2002. 


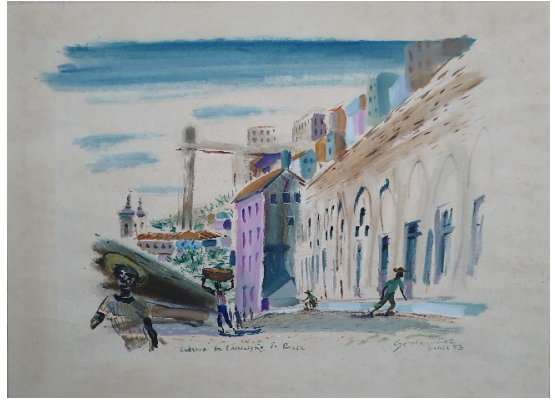

Aquarela de Gori Muñoz realizada durante sua viagem pela Bahia, para buscar locações do filme María Masdalena, de Carlos Hugo

Christensen, 1954. Acervo de María Antonia Muñoz-Malajovich. valor fotográfico, deixando zonas com diferentes luminosidades e possibilitando a profundidade no enquadre.

Nas palavras do crítico Domingo Di Núbila (1960) ${ }^{10}$, “Gori Muñoz iniciou a decoraçáo realmente funcional, como parte do relato cinematográfico e como elemento decisivo no estabelecimento de seu ambiente, clima e unidade estética”.

Gori também realizou várias exposiçóes cenográficas coletivas. Por seu trabalho como cenógrafo, recebeu 29 prêmios $^{11}$ da Asociación de Cronistas, do Instituto de Cinematografía e da Academia de Artes Cinematográficas de la Argentina. Algumas vezes foi declarado hors concours.

10 Domingo Di Núbila. Historia del Cine Argentino. Buenos Aires, Cruz de Malta, 1960.

11 O certamen hispanoamericano de Madrid (1948) premiou a cenografia de Dios se lo pague, mas devido à sua condição de espanhol e exilado ele não recebeu o prêmio, a crítica Rosa Peralta detalha essa questão em sua tese. 


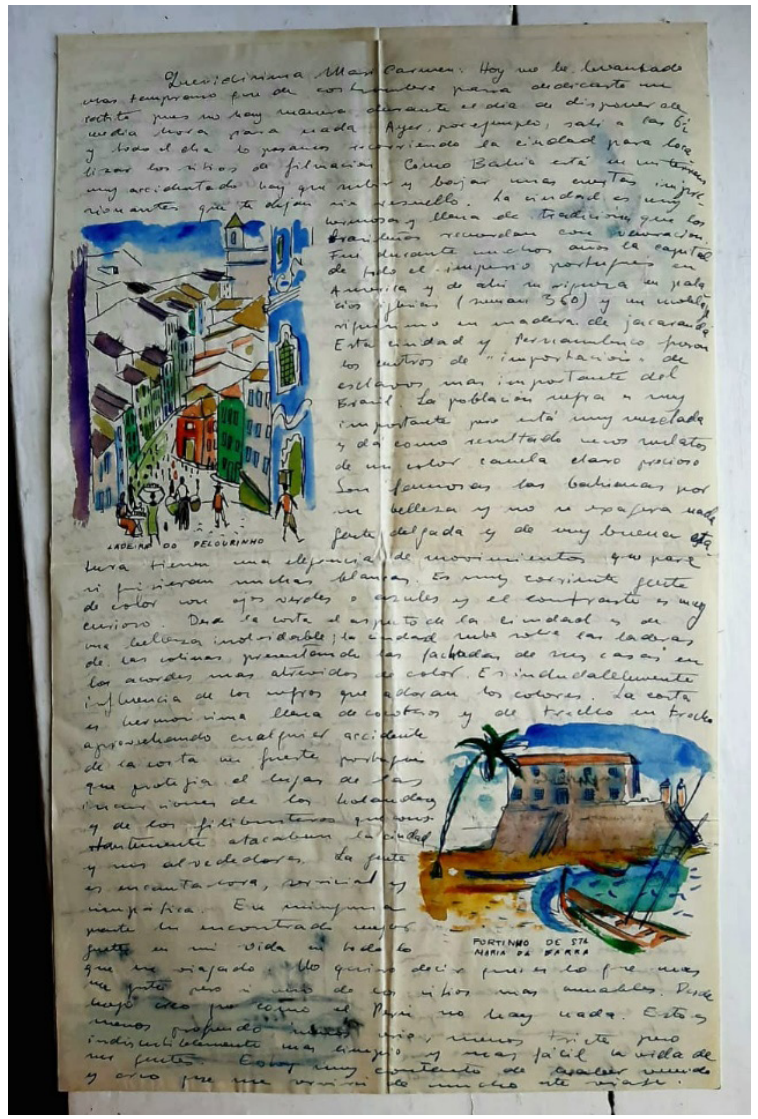

Carta de Gori Muñoz a Mari-Carmen durante sua viagem à Bahia para buscar locações para o filme María Masdalena, de Carlos Hugo Christensen, 1954. Acervo de Carmen Muñoz-Bernand.

Do cinema, além do trabalho em equipe e do ambiente do estúdio, meu pai gostava também da possibilidade de realizar filmagens externas e de procurar o ambiente ideal. Por conta disso, viajou por vários países de América: Argentina, Uruguai, Chile, Peru, Brasil, Estados Unidos. 
Registrou suas observaçóes em desenhos cheios de vida com os quais montou a exposição Carpeta de Viajes (Galería Siglo XX, 1966). De certo modo, reviveu o sonho da expedição do Ártabro ao Amazonas.

Minha irmã, Carmen Muñoz-Bernand, destaca os relatos de Gori em relação a sua viagem pelo Brasil ${ }^{12}$ - um país importante para ele -, especificamente à Bahia, onde ficou amigo de Jorge Amado, a quem conheceu por intermédio do pintor Carybé, um pintor argentino muito brasileiro, cujas visitas seguem vivas em nossas memórias infantis, mas, especialmente nas de Carmen.

\section{M.S.: Como era o cotidiano da família?}

M.A.M.M: A vida social dos exilados espanhóis era muito ativa: estreias, homenagens, exposições, banquetes, tertúlias em cafés, visitas aos amigos. Longe das famílias originárias, no exílio formaram-se outras por afinidade, tanto ou mais sólidas que as tradicionais.

E nesse meio cultural vivo, Gori engatilhou filmes e obras de teatro em um ritmo de trabalho vertiginoso com apenas quatro ou cinco horas de sono diário e uma vida social intensa, compartilhada com Mari-Carmen.

Mari-Carmen não retomou sua carreira de atriz, mas teve muito sucesso como empresária e desenhista de roupas infantis. Ela nos deixou vários escritos e um delicioso livro de memórias ${ }^{13}$. Sua dedicação foi fundamental

12 Para o filme María Magdalena, de Carlos Hugo Christensen. Argentina Sono Film, 1954.

13 María del Carmen García Antón. Visto al Pasar: República, Guerra y Exilio. A Coruña: Ediçôes do Castro, 2002. 
para congregar os amigos, que circulavam em nossa casa desde as tardes de domingo e ficavam, nunca menos de oito, para o jantar. Sempre animada e pronta para acolher a todos, como por arte de magia saíam de suas máos paellas e favadas.

Nas tertúlias de domingo, a conversa passava de um tema a outro, da última estreia a um artigo polêmico ou um acontecimento político, mas sempre recaia na guerra. Quando os ânimos esquentavam, uma piada ou um comentário agudo de Gori reestabelecia a ordem e o equilíbrio. Minha irmá e eu ajudávamos a nossa mãe e participávamos das conversas. Havia amigos constantes, como Rafael Alberti e María Teresa León, nossos vizinhos por algum tempo. Nós sempre brincávamos com a filha deles, Aitana. No Natal de 1958, ele me presenteou com um poema dedicado a mim.

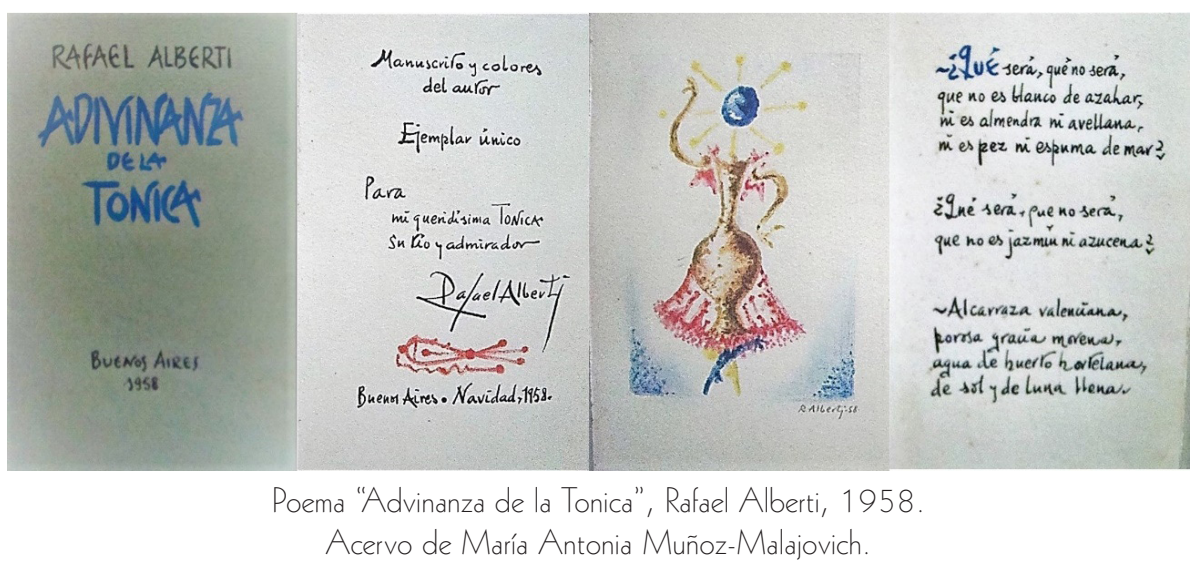




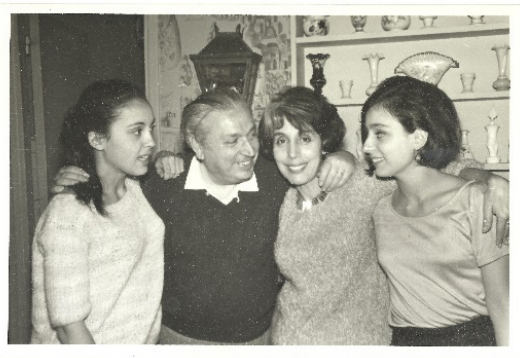

"Los cuatro". Carmen Muñoz-Bernand, Gori Muñoz, Mari-Carmen García Antón e María Antonia Muñoz-Malajovich na casa de Buenos Aires, 1962. Foto Gaspar. Acervo de María Antonia Muñoz-Malajovich.
M.S.: Seu pai presenciou os anos peronistas e viveu para ver a morte de Franco. Como lidou com essas situaçóes?

M.A.M.M: Em tempos peronistas não eram poucas as críticas dos espanhóis ao regime, nem complacentes os comentários sobre a guerra fria e o capitalismo. Nós, as crianças, crescemos com o lema de "no se repite fuera de

casa lo que se escucha aqui dentro".

Apesar de existir perseguiçóes no ambiente do cinema ${ }^{14}$, elas nunca atingiram meu pai. Ele atribuía essa proteção a seu trato com Evita Perón durante sua trajetória como atriz, nos estúdios cinematográficos; mais tarde ela teria ordenado que "al gallego no me lo toquen". Inclusive, ela se dispôs a ajudar Gori a tirar da Espanha seu irmão Antonio, doente e recém-saído do cárcere franquista. A recusa de Antonio e sua morte causaram grande tristeza a meu pai.

Minha irmã e eu (que nasci em Buenos Aires) frequentamos um colégio francês. Com a vigilante supervisão dos amigos de domingo aprendemos a combinar a cultura francesa e a espanhola. Montávamos obras de Molière com cenografia de Gori e líamos poesia espanhola e Pérez Galdós. Também

14 Fulano no corre, era a orientação das autoridades sobre quem caia em desgraça. 
aprendemos a cantar zarzuelas, dançar sevillanas e tocar as castanholas. Vivemos um quebra-cabeças cultural, amalgamado mais tarde no crisol da Universidad de Buenos Aires, onde minha irmã Carmen se formou em Antropologia e eu em Ciências Biológicas.

As festas de Natal (em casa dos Prados, dos Casona e mais tarde na dos Nogués) e Ano Novo (em nossa casa) eram divertidíssimas; todos dançávamos, montávamos números de Music Hall, cantávamos as cançôes da guerra e, em pé, La Internacional. Brindava-se pela morte de Franco e nosso próximo regresso à Espanha. Aliás, minha irmã Carmen relembra os relatos de Gori sobre os dias que passou no Harlem, com um amigo portoriquenho, nessa viagem meu pai preparou a cenografia para a apresentação de um espetáculo musical em Buenos Aires. Todas essas viagens e o encanto que ele tinha pelos diferentes sotaques da América -algo nem sempre compartilhado por outros exilados- e seu vivo interesse pelos escritores e poetas latino-americanos influiu tremendamente no interesse de Carmen pela antropologia dos ameríndios.

Mas, voltando à questáo do franquismo e à morte do caudilho, com o passar do tempo, ficou evidente que o futuro não seria assim. Alguns exilados morreram muito jovens, outros náo resistiram à saudade e regressaram definitivamente. Mari-Carmen voltou brevemente para ver a sua mãe. Gori nunca. E quando finalmente Franco morreu, ele me disse tristemente "para mí, es tarde". O que não nos impediu de bebericar um bom champagne.

Em 1958, Gori foi diagnosticado com o mal de Parkinson. Lutou valentemente contra a doença, mas pouco a pouco foi definhando. Um 
dia fechou sua caixa de pinturas e disse "no voy a pintar más". A gente soube que a morte se aproximava. Quis ser cremado e pediu para MariCarmen jogar suas cinzas no mar. "Ellas solas sabrán encontrar el camino de Valencia".

\section{REFERÊNCIAS BIBLIOGRÁFICAS:}

ANTÓN, MARI-CARMEN. Visto al Pasar: República, Guerra y Exilio. A Coruña: Ediçôes do Castro, 2002.

DI NÚBILA, DOMINGO. Historia del Cine Argentino. Buenos Aires, Cruz de Malta, 1960.

Maria Magdalena. Direção: Carlos Hugo Christensen. Produção: Argentina Sono Film, Argentina, 1954.

MUÑOZ, GORI \& CARISOMO, Berenguer. Cuando Buenos Aires era Colonia. Buenos Aires: Editorial Aguilar, 1960.

MUÑOZ, GORI "Problema y trascendencia de la escenografía”. Séptimo Arte, Buenos Aires, 1946.

MUÑOZ, GORI, "Evolución de la Escenografía”. Heraldo del Cine, Buenos Aires, 1950.

MUÑOZ, GORI. Ni en cap mapa, ni en cap història. Universitat de València: Ed. R. Peralta. 2007.

MUÑOZ, GORI. Toros y toreros del Río de la Plata. Buenos Aires: Shapire Editor, 1970.

PERALTA GILABERT, ROSA. La Escenografía del Exilio de Gori Muñoz. Valencia: Ediciones de la Filmoteca. Instituto Valenciano de Cinematografía Ricardo Muñoz Suay, 2002. 
ZYLBERMANN, DANA. El aporte de los inmigrantes al cine argentino: Gori Muñoz y el desarrollo de la escenografía como elemento dramático. Escenauno, número 3, 2015.

71. Gori Muñoz em http://margaritaxirgu.es/castellano/vivencia2/71 corimc/ 71gorimc.htm

Gori Muñoz em https://www.imdb.com/name/nm0616417/ 